\title{
Role of lung ultrasonography in postoperative fluid management in patients with severe preeclampsia
}

\author{
Ahmed MA Ismail ${ }^{\mathrm{a}}$, Salah A Mohammed ${ }^{\mathrm{a}}$, Mohamed AW Ezzat ${ }^{\mathrm{b}}$, Hamza AA Mahmoud ${ }^{\mathrm{a}}$ \\ ${ }^{a}$ Anesthesia, intensive care and pain management department, Sohag Faculty of medicine, Sohag \\ University. ${ }^{\mathrm{b}}$ Internal medicine department, Sohag Faculty of medicine, Sohag university.
}

\begin{abstract}
Background:severe preeclampsia (PET) is one of the hypertensive diseases of pregnancy associated with significant morbidity and mortality and require special monitoring, lung ultrasonography is a novel monitoring and diagnostic tools in intensive care and widely used nowadays with early detection of pulmonary oedema.
\end{abstract}

Patients and Methods:this was a cross sectional study of 55 patients with severe preeclampsia,35 case with eclampsia and 60 healthy controls. Lung ultrasonography was done to detect B lines in 12 lung zone postoperatively in both cases and controls fluid input and output is encounted.

Results:Median (Min- Max) of lung sonar was higher in severe PET than in controls $\mathrm{p}$ value $=.0001$. B lines were observed in $47.2 \%$ and $8.3 \%$ in eclampsia ,severe PET and controls respectively. There was highly statistically significant difference between cases and controls as regards input and output as ( $\mathrm{P}=.005),(\mathrm{P}=.003)$ respectively as input and output was higher in control group than cases group) While there was no statistical significance difference between cases and controls as regards net balance as $(\mathrm{P}=.09)$. complications occur in higher percentage in cases than control.

Conclusions: Restrictedfluid policy is indicated with the finding of B pattern especially with higher lung ultrasound score. Early management in patients with high B line score (pulmonary congestion) even before development of clinical manifestations should be considered.

Keywords: severe preeclampsia; eclampsia; lung ultrasonography; B lines.

\section{Introduction}

Severe PET is characterized by systolic blood pressure $\geq 160 \mathrm{~mm} \mathrm{Hg}$ and diastolic blood $\geq$ $110 \mathrm{~mm} \mathrm{Hg}$ on two occasions 4 hours apart, proteinurea> $300 \mathrm{mg}$ per $24 \mathrm{~h}$ urine collection after 20 weeks of gestation with eieher thrombocytopenia (platelet count less than 100,000), impaired liver function as indicated by elevated liver enzymes (to twice normal level), epigastric pain not responding to medications, progressive renal impairment(double serum creatinine from baseline within 24 hours) pulmonary oedema or new onset visual or cerebral disturbances (Zetterstrom et al ., 2005).

In patients with severe PET accurate assessment of maternal hemodynamics is fundamental for appropriate fluid management. Inadequate intravascular volume results in decreased oxygen delivery to tissues and exacerbates organ dysfunction . fluid excess can lead to fluid extravasation and pulmonary 
edema,the risk of fluid over-resuscitation is especially high in women with PET (Douglas and Walley, 2014).

Lung ultrasound provide a great benefits, inearly diagnosis of important lung pathology such as pulmonary edema ( through detection of B lines that's laser like beam that correlate with pulmonary congestion), pleural effusion, consolidation, and pneumothorax (Volpicelli et al., 2012).

$=\mathrm{B}$ 'lines describe the presence of at least three hyperechoic lines perpendicular to the pleural line. The number of these vertical $=\mathrm{B}$ 'lines depends on the degree of lung aeration loss and their intensity increases with inspiratory movements.(Soldati et al., 2006). They are distinguished from each other depending on their average distance in lines $\mathbf{B 3}$ and B7, where the distance is _ $\mathbf{3} \mathrm{mm}$ and $\mathbf{7} \mathrm{mm}$, respectively. The mean distance between the B lines is measured at their origin either with a linear or a convex transducer. Their distance provides important clinical information (Lichtenstein et al., 2004).

A distance between multiple _B 'lines $-3 \mathrm{~mm}$ (B3 lines) is correlated with a ground glass pattern. A separation of artifacts of approximately $7 \mathrm{~mm}$ indicates thickening of the interlobular septa (B7 lines)

\section{Materials and Methods}

- Study design; a cross sectional, hospitalbased study carried out on patients with severe preeclampsia and eclampsia and healthy parturient undergone caesarian section (for indication other than severe PET and eclampsia) as a control group attending for delivery in Sohag University Hospitals in the period from October 2018 to October 2019.
- Sample size 55 patients with severe preeclampsia and 35 patients with eclampsia in relation to 60 age matched healthyparturient as controls

- Target population

a) Inclusion criteria: Patients with severe preeclampsia (hypertension > $160 / 110$, proteinurea up to 2 gram, severe persistent epigastric pain, elevated liver enzymes, thrombocytopenia < 100000, visual and cerebral disturbances, and pulmonary oedema ) and patients with eclampsia (the same previous criteria plus eclamptic fits)

b) Exclusion criteria:Patient with known: Hypertension, Cardiac disorders Pulmonary disorders and Renal disorders.

\section{Methodology}

After cases admission to ICU and controls admission to Obstetrics Department, anesthesia sheet was revised to check ; Age, diagnosis, BMI, gestational age, gestational history, parity, type of anesthesia, pulse, blood pressure, fluids, proteinurea and other criteria of severe PET and laboratory investigations were checked ( $\mathrm{CBC}$, urea and creatinine, liver function tests, urine analysis) and fluid intake and output were also revised with net balance (that is the difference between intake and output).

\section{Lung ultrasonography}

A convex probe (frequency $5 \mathrm{HZ}$ ) of (SONOACE 8000 SE) ultrasonography device was used to perform 12 lung zone ultrasonography, patient lie on supine position then chest is divided into 12 zone 4 zones on anterior chest wall (Right and Lt upper anterior and Right and Left lower anterior ), 4 zones on the posterior chest wall (Right and Left upper posterior and Right and Left lower posterior), 4 lateral zones ( 2 upper and lower right lateral and 2 upper and lower left lateral zones) 
In each zone examined the increased amount of extravascular lung water (EVLW) can be diagnosed by multiple B-lines or _comet tails 'B-lines are defined as discrete laser-like vertical hyperechoic reverberation artifacts that arise from the pleural line and extend to the bottom of the screen without fading, and move synchronously with lung sliding.

The sum of the B-lines found on each zone is counted four score in each zone was encounted

0 if $\mathrm{B}$ lines less than 3 in number

$\mathbf{1}$ if there was clear number of multiple visible B-lines with horizontal spacing between adjacent B lines $\leq 7 \mathrm{~mm}$

2 multiple B lines fused together that were difficult to count with horizontal spacing between adjacent $\mathrm{B}$ lines $\leq 3 \mathrm{~mm}$, including white lung'

3 pulmonary consolidation (C), hyperechoic lung tissue, accompanied by dynamic air bronchogram

So the score of each zone was ranging from $\mathbf{0}$ to $\mathbf{3}$, Then the sum of scores of all zones (12) was enconunted that range from 0 to 36 (Volpicelli et al., 2014).

\section{Statistical analysis}

\section{Data entry}

After completion of data collection, data was revised, coded and fed to the computer and analyzed using MedCalc program version 17. Quantitative data were tested using Kolmogorov -Smirnov (K.S) test and described using Mean and Standered deviation for normally distributed data, while Median and Minimum and Maximum for abnormally distributed data. Qualitative data were described using number and percent. significance level for all statistical tests was set as $\mathrm{P}<0.05$ The choice of either test was determined by testing distribution of variables by Kolmogorov -Smirnov test.

\section{Results}

Socio-demographic characteristics of study sample

In our study, there was no statistically significant difference between 3 groups regarding age as $(\mathrm{P}=.867)$, while there was statistically significant difference between 3 groups as regards $\mathrm{BMI}$ as $\left(\mathrm{P}=.005^{*}\right)$ where the control has a higher BMI than cases groups. table (1)

Intraoperative needed fluid (Input \& output \&net balance) in cases and controls

There was highly statistically significant difference between cases and controls as regards input and output as ( $\mathrm{P}=.005),(\mathrm{P}=.003)$ respectively as input and output was higher in control group than cases group table (2)

While there was no statistical significance difference between cases and controls as regards net balance as $(\mathrm{P}=.09)$ table (2).

Comparison between cases and controls as regards Lung ultrasound score

There was highly statistical significance difference between cases and controls as regards Lung ultrasound score (, $\mathrm{P}=.0001)$ (table3) (fig1).

Eclampsia cases have the highest LUS score followed by cases with severe PET, most of controls have normal lung.

\section{Postoperative complications detected in cases group}

3 patients in cases group develop pulmonary oedema representing $3.3 \%$ of cases. 
Table (1): Socio-demographic characteristics of cases and controls

\begin{tabular}{|c|c|c|c|c|}
\hline & \multicolumn{2}{|c|}{ Cases } & \multirow{2}{*}{$\begin{array}{c}\text { Controls } \\
(\mathbf{N}=60)\end{array}$} & \multirow{2}{*}{$\begin{array}{c}\text { Test of significance } \\
\text { (p) }\end{array}$} \\
\hline & $\begin{array}{l}\text { Preeclampsia } \\
\quad(N=55)\end{array}$ & $\begin{array}{c}\text { Eclampsia } \\
(\mathrm{N}=35)\end{array}$ & & \\
\hline \multicolumn{5}{|l|}{ Age(years) } \\
\hline Mean \pm SD & $23.69 \pm 3.9$ & $24.48 \pm 4.9$ & $25.450 \pm 4.4813$ & $(\mathrm{~F}=.144, \mathrm{P}=.867)$ \\
\hline BMI $\left(\mathrm{Kg} / \mathrm{m}^{2}\right)$ & \multirow{2}{*}{$23.45 \pm 3.6$} & \multirow{2}{*}{$23.54 \pm 2.57$} & \multirow{2}{*}{$25.08 \pm 2.9875$} & \multirow[t]{2}{*}{$(\mathrm{F}=5.35, \mathrm{P}=.005 *)$} \\
\hline Mean \pm SD & & & & \\
\hline
\end{tabular}

Table (2): Intraoperative needed fluid in cases and controls.

\begin{tabular}{|c|c|c|c|c|}
\hline & \multicolumn{2}{|c|}{ Cases } & \multirow{2}{*}{$\begin{array}{l}\text { Controls } \\
(\mathrm{N}=60)\end{array}$} & \multirow{2}{*}{$\begin{array}{l}\text { Test of significance } \\
\text { (p) }\end{array}$} \\
\hline & $\begin{array}{l}\text { Preeclampsia } \\
\quad(\mathrm{N}=55)\end{array}$ & $\begin{array}{c}\text { Eclampsia } \\
(\mathbf{N}=35)\end{array}$ & & \\
\hline Input & \multirow[b]{2}{*}{$\begin{array}{c}1209.09 \mathrm{ml} \\
\pm 248.9\end{array}$} & \multirow[b]{2}{*}{$\begin{array}{c}1014.29 \mathrm{ml} \\
\pm 353.26\end{array}$} & \multirow[b]{2}{*}{$1216.67 \mathrm{ml} \pm 336.56$} & \multirow[b]{2}{*}{$\left(\mathrm{F}=5.46, \mathrm{P}=.005^{*}\right)$} \\
\hline Mean \pm SD & & & & \\
\hline $\mathbf{P 1}$ & \multicolumn{2}{|c|}{$.013 *$} & & \multirow{5}{*}{$(\mathrm{F}=6.1, \mathrm{P}=.003 *)$} \\
\hline $\mathbf{P 2}$ & & \multicolumn{2}{|c|}{$.008 *$} & \\
\hline $\mathbf{P 3}$ & .9 & \multirow{3}{*}{$\begin{array}{c}477.14 \mathrm{ml} \\
\pm 222.4\end{array}$} & & \\
\hline Output & \multirow{2}{*}{$\begin{array}{c}615.45 \mathrm{ml} \\
\pm 307.3\end{array}$} & & $875.83 \mathrm{ml}$ & \\
\hline Mean \pm SD & & & \pm 837.4 & \\
\hline P1 & \multicolumn{2}{|c|}{.6} & & \\
\hline $\mathbf{P 2}$ & & \multicolumn{2}{|c|}{$.004 *$} & \\
\hline $\mathbf{P 3}$ & $.047 *$ & & & \\
\hline \multicolumn{5}{|l|}{ Net balance } \\
\hline Mean \pm SD & $\begin{array}{c}593.64 \mathrm{ml} \\
\pm 254.6\end{array}$ & $\begin{array}{l}534.29 \mathrm{ml} \\
\pm 293.5\end{array}$ & $\begin{array}{c}490.83 \mathrm{ml} \\
\pm 212.43\end{array}$ & $(\mathrm{~F}=2.459, \mathrm{P}=.09)$ \\
\hline
\end{tabular}

Table (3): Comparison between study groups as regards Lung ultrasound score. 


\begin{tabular}{|c|c|c|c|c|}
\hline & \multicolumn{2}{|c|}{ Cases } & \multirow{2}{*}{$\begin{array}{l}\text { Controls } \\
(\mathbf{N}=60)\end{array}$} & \multirow{2}{*}{$\begin{array}{c}\text { Test of significance } \\
\text { (p) }\end{array}$} \\
\hline & $\begin{array}{l}\text { Preeclampsia } \\
(\mathrm{N}=55)\end{array}$ & $\begin{array}{c}\text { Eclampsia } \\
(\mathrm{N}=35)\end{array}$ & & \\
\hline Lung ultrasound score & \multirow[b]{2}{*}{$0(0-20)$} & \multirow[b]{2}{*}{$7(0-20)$} & \multirow[b]{2}{*}{$0(0-2)$} & \multirow[b]{2}{*}{$(\mathrm{H}=40.8, \mathrm{P}=.0001 *)$} \\
\hline Median (Min -Max) & & & & \\
\hline P1 & \multicolumn{2}{|c|}{.08} & & \\
\hline $\mathbf{P 2}$ & & \multicolumn{2}{|c|}{$.0001 *$} & \\
\hline P3 & $.0001 *$ & & & \\
\hline
\end{tabular}

$\mathrm{H} ;$ Kruskall Wallis test

P: Significance between groups; p1 Significance between preeclampsia and eclampsia, P2: Significance between control and eclampsia, p3: Significance between pre-eclampsia and controls Sig between groups assessed by Mann Whitney test.

*: statistically sig

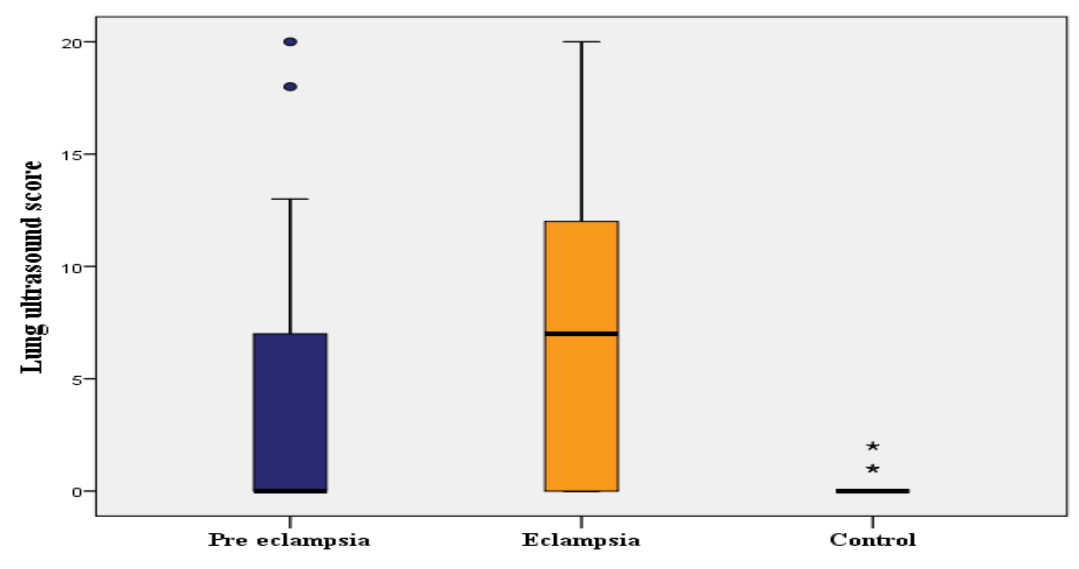

Fig (1): Comparison between study groups as regards Lung Sonar

\section{Discussion}

In the present study, there was no statistically significant difference between 3 groups regarding age as $(\mathrm{P}=.867)$, which was similar toAmbrozic et al (2017) who found in Caucasian women that no significant difference was found for age. Age in case group was 28 (21-44), and in control was 33 (24-42), p 0.54 .

In the current study, there was statistically significant difference between 3 groups as regards BMI as $\left(\mathrm{P}=.005^{*}\right)$. BMI was $23.45 \pm 3.6$ and $23.54 \pm 2.57$ versus $25.08 \pm$ 2.9875 in preeclampsia and eclampsia versus control respectively, which wasn't similar to
Motedayen et al (2019) who found that a significant relationship was found between BMI and the risk of preeclampsia. The mean BMI values in their studies were 25.13, 27.42, and $26.33 \mathrm{~kg} / \mathrm{m} 2$ in the healthy, mild, and severe preeclamptic groups, respectively. While Ambrozic et al (2017) found in Caucasian women with preeclampsia that no significant difference for BMI.

In the present work, there was highly statistically significant difference between 3 groups regarding input of fluid as $(\mathrm{P}=.005)$. In preeclampsia input was $1209.09 \pm 248.9$, and in eclampsia $1014.29 \pm 353.26$ versus $1216.67 \pm 336.56$ in controls. The mean of input was lower in severe PET and eclampsia 
cases than controls which was in line with Zeeman et al (2003) who recommended fluid restriction in postoperative management of severe preeclampsia in preeclampsia there is often of a leakage of waterand plasma from the intravascular space, due to underlying endothelial damage. This results in pulmonary edema.

Additionally, Ciumanghel et al (2018)reported that volume overload is associated with interstitial lung edema which increases the diffusion distance for oxygen and nutrients and limits the removal of toxic byproducts of cellular metabolism.

In the present work, there was highly statistically significant difference between 3 groups regarding output of fluid as $(\mathrm{P}=.003)$. Fluid output decrease in the cases compared to the control. In preeclampsia output was 615.45 \pm 307.3 and in eclampsia $477.14 \pm 222.4$ versus $875.83 \pm 837.4$ in the control. This can be explained by that fluid input in severe PET and eclampsia was lower than control. While there was no statistically significant increase in net balance compared to the control as $(\mathrm{P}=.09)$.

In the current, there was statistically significant difference between 3 groups regarding lung sonar as median (Min -Max) was 7(0-20) in eclampsia, 0(0-20) in preclampsia, and 0(02 ) in controls. $p$ value $=.0001$. Median $($ MinMax) of lung sonar was higher in both eclampsia and severe PET. B lines were observed in $62.8 \%, 47.2 \%$ and $8.3 \%$ in eclampsia ,severe PET and controls respectively.
This was in agreement with Zieleskiewicz et al (2014) who found that B lines were observed in patients with severe PET and no B lines were observed in controls. Ambrozic et al (2017) also reported that severe preeclampsia was associated with an increase in extravascular lung water,which could in part be caused by disturbed diastolic left ventricular function that is commonly seen in those patients.

In the current study, pulmonary oedema was presented in $3.3 \%$ of cases (preclampsia and eclampsia), which was in agreement with Jantasing and Tanawattanacharoen (2011)who found that pulmonary edema was in $3.4 \%$ of cases .Norwitz et al (2002) reported that pulmonary oedema may occur in up to $2.9 \%$ of women with severe pre-eclampsia mainly postpartum.

\section{Conclusion}

Lung ultrasonography is mandatory in postoperative monitoring in patients with severe PET and eclampsia as they can adjust management.

Restricted fluid policy is indicated with the finding of $\mathrm{B}$ pattern especially with higher lung ultrasound score.

Early management in patients with high B line score (pulmonary congestion) even before development of clinical manifestations shouldbe considered. 


\section{References}

Ambrozic, J., BrzanSimenc, G., Prokselj, K., Tul, N., Cvijic, M., \&Lucovnik, M,(2017).Lung and cardiac ultrasound for hemodynamic monitoring of patients

Ciumanghel, A., Siriopol, I., Blaj, M., Siriopol, D., Gavrilovici, C., andCovic, A, (2018).B-lines score on lung ultrasound as a direct measure of respiratory dysfunction in ICU patients with acute kidney injury. International Urology and Nephrology; 50(1), 113119.

Douglas J Douglas and Keith R Walley, (2014). Fluid choices impact outcome in septic shock; current opinion in critical care 20: 378-384.

Jantasing, S., \&Tanawattanacharoen, S, (2011).Perinatal Outcomes in Severe Preeclamptic Women between 24-33+ 6 Weeks 'Gestation. Journal of the Medical Association of Thailand; 91(1), 25.

\section{Lichtenstein D, Goldstein I, Mourgeon E,} Cluzel P, Grenier $P$ et al, (2004).Comparative diagnostic performances of auscultation, chest radiography, and lung ultrasonography in acute respiratory distress syndrome. Anesthesiology; 100: 9-15.

Motedayen, M., Rafiei, M., RezaeiTavirani, M., Sayehmiri, K., \&Dousti, M, (2019). The relationship between body mass index and preeclampsia: A systematic review and metaanalysis. International journal of reproductive biomedicine (Yazd, Iran); 17(7), 463-472.

Norwitz, E. R., Hsu, C.-D., \&Repke, J. T, (2002).Acute complications of preeclampsia.Clinical obstetrics and gynecology; 45(2), 308-329.
withseverepre-eclampsia.Ultrasound in $\mathrm{Ob}$ stetrics \& Gynecology; 49(1), 104-109.

Soldati G, Testa A, Pignataro G, Carbone L, Portale G, Nicola G and et al, (2006). The ultrasonographic deep sulcus sign in traumatic pneumothorax. Ultrasound Med. Biol.;32: 1157-63.

VolpicelliG, Elbarbary M, Blaivas M, Lichtenstein D, Mathis G, Kirkpatrick A et al(2012). International evidence-based Recommendations for point-of-care lung ultrasound. Intensive Care Med; 38:577-91.

Volpicelli G, Skurzak S, Boero E, Carpinteri G, Tenqattini M, Stefanone V, et al, (2014). Lung ultrasound predicts well extravascular lung water but is of limited usefulness in the prediction of wedge pressure; 121:3207.

Zeeman, G., McIntire, D., \&Twickler, D, (2003). Maternal and fetal artery Doppler findings in women with chronic hypertension who subsequently develop superimposed preeclampsia. The Journal of Maternal-Fetal \& Neonatal Medicine; 14(5), 318-323.

Zieleskiewicz, L., Contargyris, C., Brun, C., Touret, M., Vellin, A., Antonini, F, (2014). Lung ultrasound predicts interstitial syndrome and hemodynamic profile in parturients with severe preeclampsia. Anesthesiology: The Journal of the American Society of Anesthesiologists; 120(4), 906-914. 